\title{
Low-temperature dilute acid hydrolysis of oil palm frond
}

\begin{abstract}
Oil palm frond (OPF) fiber, a lignocellulosic waste from the palm oil industry, contains high cellulose and hemicellulose content, thus it is a potential feedstock for simple sugars production. This paper describes the two-stage hydrolysis process focusing on the use of lowtemperature dilute acid hydrolysis to convert the hemicellulose in OPF fiber to simple sugars (xylose, arabinose, and glucose). The objective of the present study was to evaluate the effect of operating conditions of dilute sulfuric acid hydrolysis undertaken in a $1 \mathrm{~L}$ self-built batch reactor on xylose production from OPF fiber. The reaction conditions were temperatures (100$140^{\circ} \mathrm{C}$ ), acid concentrations (2-6\%), and reaction times (30-240 $\left.\mathrm{min}\right)$. The mass ratio of solid/liquid was kept at 1:30. Analysis of the three main sugars glucose, xylose, and arabinose were determined using high-pressure liquid chromatography. The optimum reaction temperature, reaction time, and acid concentration were found to be $120^{\circ} \mathrm{C}, 120 \mathrm{~min}$, and $2 \%$ acid, respectively. Based on the potential amount of xylose $(10.8 \mathrm{mg} / \mathrm{mL}), 94 \%$ conversion $(10.15 \mathrm{mg} / \mathrm{mL})$ was obtained under the optimum conditions with small amount of furfural $(0.016 \mathrm{mg} / \mathrm{mL})$. To enhance the effectiveness of dilute acid hydrolysis, the hydrolysis of OPF fiber was also performed using ultrasonic-pretreated OPF fiber. The effects of ultrasonic parameters power (40-80\%) and ultrasonication times (20-60 $\mathrm{min}$ ) were determined on sugar yields under optimum hydrolysis conditions ( $2 \%$ acid sulfuric, $120^{\circ} \mathrm{C}$ and $120 \mathrm{~min}$ ). However, the use of ultrasonication was found to have detrimental effect on the yield of simple sugars due to the 10-fold increase in the formation of furfural.
\end{abstract}

Keyword: Dilute acid hydrolysis; Lignocelluloses; Oil palm frond (OPF); Optimization; Ultrasound; Xylose 